\title{
Physicians combat opioid crisis
}

\author{
- Cite as: CMAJ 2017 January 9;189:E44-5. doi: 10.1503/cmaj.109-5361
}

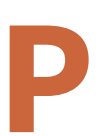
hysicians promised new prescribing guidelines, better monitoring of high-prescribers, improved medical education and other measures to address Canada's opioid crisis in the Joint Statement of Action to Address the Opioid Crisis, released at a national opioid summit on Nov. 19.

Nine of the 42 partner organizations that developed the statement are medically related. The new statement, released at the conclusion of the opioid conference and summit, Nov. 18-19 in Ottawa, aims to address root causes and reduce harms associated with opioid use. One of those root causes is excessive prescribing at high doses.

Canada's dispensing levels are the second highest in the world, said Federal Health Minister Dr. Jane Philpott. In 2015, doctors wrote one prescription for every two Canadians, according to The Globe and Mail.

"We're probably in excess of 2000 deaths per year due to opioid overdoses, six or seven each day," said Ontario Health Minister Dr. Eric Hoskins, who cohosted the conference and summit with Philpott. "We need to stop the escalation...," he said.

New Canadian guidelines for the use of opioids in chronic non-cancer pain will address current gaps and are more thoroughly evidence based. Its authors estimate the guidelines will be submitted for publication by March 2017. The Canadian Medical Association (CMA) says it will disseminate new tools and resources to promote uptake, use and impact of the guidelines among its 83000 members.

The CMA will also survey members on the "facilitators and barriers" to implementing the guidelines, and to identify system issues such as access to pain and addiction treatment options.

Many have argued that problem prescribing began with pharma-sponsored education in medical schools. The Association of Faculties of Medicine of Canada pledged in the action statement to review opioid educational activities in Canada's 17 faculties of medicine, and create and share a repository of educational products that reflect best practice by November 2017.

Education was also the focus of many initiatives from medical organizations,

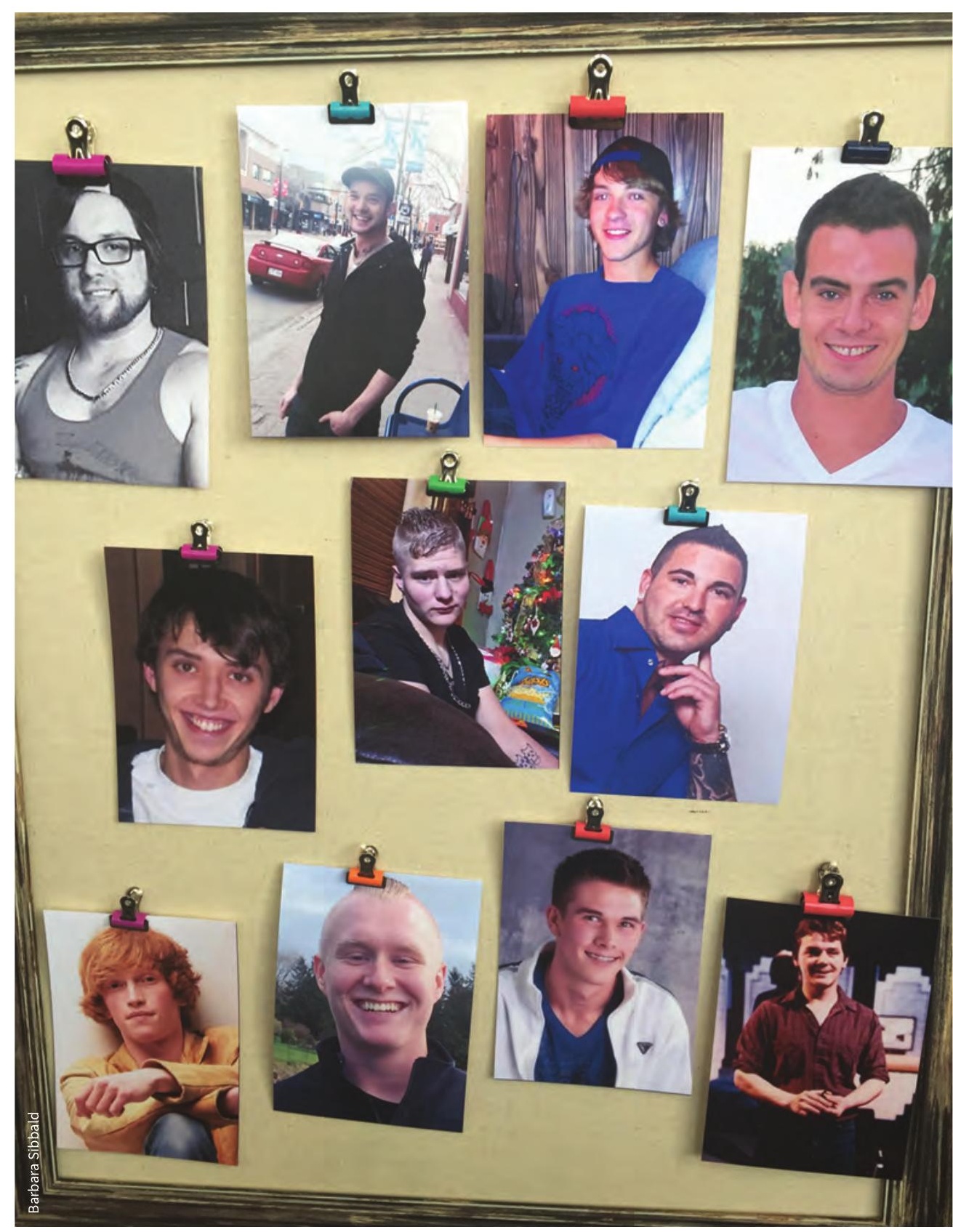

Photos of Canadians who recently died from opioid poisoning were tacked to a board outside a Nov. 18 opioid conference in Ottawa. 
including The College of Family Physicians of Canada and the Canadian Medical Protective Association (CMPA), which provides medical liability insurance to doctors. The CMPA also pledged to monitor and report on medicolegal issues and lessons learned related to opioid prescribing.

Provincial colleges of medicine from Alberta, British Columbia, Newfoundland and Labrador, Ontario and Quebec also helped develop the statement of action and made specific commitments. Most promised to provide more education and ensure doctors adhered to prescribing guidelines.

Statistics on the scope of the problem are incomplete, but experts report that 622 people died in British Columbia from opioid overdoses in the first 10 months of this year while, in Alberta, 338 died between January and September. Ontario, where per-capita rates of prescription opioid use are the highest in Canada, reported 700 deaths in 2015.

Medical colleges in Alberta, BC, Ontario and Quebec agreed to identify high-risk prescribing.

The College of Physicians and Surgeons of Alberta will provide every physician who prescribes opioids and/or benzodiazepines in the community with a comparative prescribing pattern report, including a list of patients whose doses exceed guidelines. By December 2017, physicians who prescribe very high doses (3000 mg or more) for chronic non-malignant pain will be required to work with a mentor to reduce the dose as much as possible for each patient.

BC's college committed to forming a prescription-monitoring oversight committee by March 2017. It will analyze data from PharmaNet and deliver reports to regulatory colleges that identify prescribing that may be unsafe.

Ontario's college recently released a strategy and plan to use a narcotics monitoring system to identify high prescribing and refer to regulatory bodies for follow up.

Le Collège des médecins du Québec and l'Ordre des pharmaciens du Québec will also monitor prescriptions to identify high-risk prescribers and at-risk patients, promote optimal use of opioids and "modify prescribing practices in hospitals, especially in surgical specialties, to reduce or eliminate the practice of systematically prescribing long-term opioids for postoperative pain management."

The joint statement of action was developed with input from 42 partner organizations, including several provincial territorial health ministries, dental, nursing, physician and other health professional association, regulatory bodies and others.

Highlighted measures include new tools and guidance for health care professionals; increased access to buprenorphinenaloxone in First Nations communities; improved addiction services; increased access to Naloxone, and increased monitoring and surveillance across Canada.

\section{Collaborative effort}

Philpott said those supporting the joint statement are "absolutely committed to respond to the serious and growing crisis related to opioids in this country." She acknowledged that the serious and complex problem "requires a concerted comprehensive, collaborative effort."

That effort will include new federal legislation, she said. To begin with, legislation will be amended to allow supervisedconsumption sites, such as the successful InSite project in Vancouver, which prevents overdose and death by monitoring those consuming or using illegal drugs.

No money was pledged to support the federal government's efforts, however, Philpott said, "We will do ongoing work to make sure this is properly resourced."

Social determinants of health and health inequity, which often underlie opioid misuse, are starting to be addressed, she added. The federal government will soon announce a national housing strategy and better access to mental health care, like cognitive behavior therapy for pain or addiction, said Philpott.

Mental health is a priority in the current Health Accord discussions among Canadian ministers of health. That accord is due early in 2017.
Philpott also acknowledged that specific resources will be needed for "further announcements on other work we are going to be doing."

"We have made it clear this is a human crisis and we will work to find the tools that are necessary," she said.

Ontario would like more federal money, said Hoskins, but the provinces and territories also have a responsibility to address this crisis. "We have to harness the resources including provincial resources to address this."

The federal government also reiterated its commitment to implementing Health Canada's Opioid Action Plan, announced in July 2016. It includes better informing Canadians about the risks; supporting better prescribing; reducing easy access to unnecessary opioids; supporting better treatment options, improving the evidence base for policy decision, and reducing the availability and harms of street drugs.

\section{State of emergency?}

The news release about the statement of action referred to the growing number of overdoses and deaths related to opioids as a "national public health emergency." However, the federal government stopped short of declaring a public welfare emergency under the federal Emergency Act as was called for by several experts at the opioid conference.

A Health Canada statement to the media clarified that the opioid crisis does not meet the criteria for the Act, which is considered a tool of last resort. Even if it were applied, the Chief Public Health Officer would not have any new or special powers, the statement said.

The joint statement of action is the federal government's second effort at developing a national opioid strategy. In 2013, The National Advisory Council on Prescription Drug Misuse released a report with 58 measures, but they were not prioritized, and responsibility for measures such as ensuring an evidence base, were never assigned to anyone.

Barbara Sibbald, CMAJ 